\title{
Identification of the molecular function of tripartite motif containing 58 in human lung cancer
}

\author{
YUAN-XIANG SHI \\ Institute of Clinical Medicine, Hunan Provincial People's Hospital, The First Affiliated Hospital \\ of Hunan Normal University, Changsha, Hunan 410005, P.R. China
}

Received April 13, 2021; Accepted May 24, 2021

DOI: $10.3892 /$ ol.2021.12946

\begin{abstract}
Lung cancer is a major public health problem worldwide, with a high associated incidence and mortality. In the present study, novel epigenetic signatures were identified through genome-wide DNA methylation microarrays. The results revealed that tripartite motif containing 58 (TRIM58), a potential tumor suppressor gene exhibited high methylation and low expression in lung cancer tissue samples compared with normal tissues. Receiver operating characteristic curve analysis demonstrated that TRIM58 may be a promising early diagnostic indicator of lung cancer. In addition, the present study analyzed the role of TRIM58 in tumorigenesis and development in lung cancer A549 cells. Wound healing assay and transwell migration assay were used to investigate cell migration, and flow cytometry analysis was used to detect apoptosis. Silencing TRIM58 accelerated the proliferation and migration of lung cancer cells. In contrast, the overexpression of TRIM58 significantly inhibited the proliferation and migration of lung cancer cells and promoted apoptosis. Gene set enrichment analysis revealed that TRIM58 expression was negatively correlated with MYC targets, $\mathrm{G}_{2} \mathrm{M}$ checkpoints and the mTORC1 signaling pathway. These results of the present study suggested that TRIM58, a potential tumor suppressor gene may serve as a novel diagnostic biomarker and therapeutic target in human lung cancer.
\end{abstract}

\section{Introduction}

According to the Cancer Statistics report published by the American Cancer Society in 2021, lung cancer is the leading cause of death in both men and women, accounting for $22 \%$ of all cancer deaths (1). In China, lung cancer ranks first among

Correspondence to: Dr Yuan-Xiang Shi, Institute of Clinical Medicine, Hunan Provincial People's Hospital, The First Affiliated Hospital of Hunan Normal University, 61 Jiefang West Road, Changsha, Hunan 410005, P.R. China

E-mail: yuanxiangshi@hunnu.edu.cn

Key words: lung cancer, early diagnosis, malignant phenotype, tripartite motif containing 58 malignant tumors in incidence and mortality and has become an important disease that endangers public health and affects people's quality of life (2). Lung cancer lacks obvious clinical symptoms in the early stage, and at the same time lacks effective early screening methods, the 5-year survival rate of lung cancer patients is less than $15 \%(3,4)$. In addition, metastasis and chemoresistance are important causes of the high mortality in lung cancer $(5,6)$. Hence, the identification of specific molecular markers and the exploration of new effective drug targets for the early diagnosis and treatment of lung cancer are urgently needed and have extremely important scientific research significance and clinical application prospects (7).

Epigenetic events are important in all aspects of biology, and numerous studies have shown that they serve key roles in carcinogenesis and tumor progression (8-10). Various mechanisms contribute to the occurrence of lung cancer, including DNA methylation. However, the specific regulatory mechanisms have not been fully elucidated (11). DNA methylation is an important epigenetic regulation and abnormal methylation can affect gene expression $(12,13)$. Molecular markers of DNA methylation for the early diagnosis and prognosis prediction of tumors and tumor-targeting drugs based on epigenetics have been widely studied, for example, the application of O-6-methylguanine-DNA methyltransferase (MGMT) DNA methylation in molecular diagnosis of glioma (14-16). The identification of DNA methylation profiles in tumors has laid the foundation for the discovery of new tumor therapeutic targets.

Tripartite motif containing 58 (TRIM58) is a member of the tripartite motif (TRIM) family (17). The TRIM protein family is a conserved protein family that plays important roles in signal transduction, innate immunity, autophagy, tumors and other functions $(18,19)$. For instance, TRIM67 inhibits the occurrence and progression of colorectal cancer by activating the p53 signaling pathway (20). The TRIM family is characterized by 3 domains (from the N-terminus to the C-end): the RING (Really Interesting New Gene) -finger domain, one or two B-boxes, and one coiled-coil domain (21). Currently, more than 80 TRIM proteins have been found in humans, most of which have the function of E3 ubiquitin ligase and regulate cell transcription, proliferation and apoptosis through the ubiquitination of target molecules, thus participating in various physiological and pathological processes in the body, such as developmental disorders, viral infections and cancer $(22,23)$. 
According to the features of the domains, the TRIM family is divided into 11 subfamilies and TRIM58 is a member of the C-IV-1 subfamily (C-I to C-XI) (24).

The main subtypes of lung cancer are lung adenocarcinoma (LUAD) and lung squamous cell carcinoma (LUSC) (25). In our previous study, we collected clinical samples of LUSC for genome-wide DNA methylation analysis and identified many new epigenetic signatures (26). In the present study 3 methylation microarray datasets (GSE63384, GSE62948 and GSE32861) of LUAD from the Gene Expression Omnibus (GEO) database were collected for the integrated analysis of large samples. Integrating the results of high-throughput screening, focusing on TRIM58, which was hypermethylated and downregulated in lung cancer. Notably, functional studies performed demonstrated that overexpression of TRIM58 inhibited cell proliferation and migration and promoted cell apoptosis. These findings suggest that TRIM58 serves a critical role in the malignant phenotype of lung cancer.

\section{Materials and methods}

DNA methylation datasets of lung cancer. The Gene Expression Omnibus (GEO) datasets (GSE63384, GSE62948 and GSE32861) were all based on the GPL8490 platform (http://www.ncbi.nlm.nih.gov/geo) (27-29). The 3 datasets selected all comprised of paired samples consisting of tumor and corresponding NTL tissues. The GSE63384 dataset included 35 stage I LUAD tissues and 35 NTL tissues; GSE62948 included 28 LUAD tissues and 28 NTL tissues and GSE32861 contained 59 LUAD tissues and 59 NTL tissues. Subsequently, these 3 datasets were used for ROC analysis.

Genome-wide DNA methylation analysis. Genome-wide DNA methylation analysis using the R package version 4.2 (http:// www.r-project.org/) (30). The linear models for microarray data (LIMMA) package (v.3.48.0) in Bioconductor was used for data processing (31). The Benjamini-Hochberg procedure in $\mathrm{R}$ package was used to calculate the adjusted P-values (32). Probes with a adjusted $\mathrm{P}<0.05$ and an absolute $\beta$ difference $\geq 0.2$ were considered differentially methylated genes (DMGs).

The Cancer Genome Atlas (TCGA) data and validation. Validation datasets were extracted from the data portal of TCGA (http://tcga-data.nci.nih.gov) (33). TCGA DNA methylation dataset: A total of 372 LUSC samples with 43 corresponding NTL samples and 460 LUAD samples with 32 corresponding NTL samples were used for performing independent DNA methylation verification. TCGA mRNA expression dataset: including 502 LUSC samples corresponding to $51 \mathrm{NTL}$ samples, and 571 LUAD samples corresponding to $58 \mathrm{NTL}$ samples for mRNA expression detection. In addition, the MethHC browser (http://methhc.mbc.nctu.edu.tw/php/index. php) was used to analyze the correlation between DNA methylation and mRNA expression (34).

Cell culture and transfection. A549, a human lung adenocarcinoma cell line was purchased from the Chinese Academy of Sciences and cultured at $37^{\circ} \mathrm{C}$ with $5 \% \mathrm{CO}_{2}$ in RPMI-1640 medium (Invitrogen; Thermo Fisher Scientific Inc.) containing 10\% fetal bovine serum (FBS, Gibco; Thermo Fisher Scientific Inc.).
To investigate the molecular functions of TRIM58, specific small interfering (si) RNA and overexpression vectors of TRIM58 were constructed. Transfection was performed $24 \mathrm{~h}$ after the cells were plated. TRIM58-siRNA was synthesized by Guangzhou RiboBio Co., Ltd. and the target sequence was 5'-GGACTATGAAGCCGGTGAA-3'. For the scrambled siRNA used as the negative control (NC) (Guangzhou RiboBio Co., Ltd.). The final siRNA (TRIM58-siRNA or scrambled siRNA) concentration was adjusted to $50 \mathrm{nM}$ and transfected with Lipofectamine ${ }^{\circledR}$ RNAiMAX (Invitrogen; Thermo Fisher Scientific Inc.). pCDNA3.1-TRIM58 vector was synthesized by Shanghai GeneChem Co., Ltd. and empty pcDNA3.1 vector was used as the negative control. The final pcDNA3.1 vector concentration was adjusted to $1 \mu \mathrm{g}$ and transfected with Lipofectamine 2000 (Invitrogen; Thermo Fisher Scientific Inc.). After transfection for $48 \mathrm{~h}$ at $37^{\circ} \mathrm{C}$, cell migration was detected and cells were collected for RNA and protein extraction.

$R N A$ extraction and reverse transcription-quantitative (RT-q) $P C R$. A549 cells were collected. TRIzol ${ }^{\circledR}$ reagent (Invitrogen; Thermo Fisher Scientific Inc.) was used to extract total RNA. The PrimeScript ${ }^{\mathrm{TM}}$ RT reagent kit (Takara Bio, Inc.) was used for reverse transcription and the standard SYBR Green PCR kit (cat. no. RR091A; Takara Bio, Inc.) was used for RT-qPCR according to the manufacturer's protocol. The PCR thermocycling conditions were as follows: initial denaturation at $95^{\circ} \mathrm{C}$ for $10 \mathrm{~min}$, followed by 40 cycles at $95^{\circ} \mathrm{C}$ for $15 \mathrm{sec}$ and $60^{\circ} \mathrm{C}$ for $60 \mathrm{sec}$. GAPDH was used as the internal reference gene and the data were calculated using the $2^{-\Delta \Delta \mathrm{CT}}$ method (35). The primer sequences used were as follows: GAPDH, forward 5'-GGAAGCTTGTCATCAATGGAAATC-3' and reverse, 5'-TGATGACCCTTTTGGCTCCC-3'; TRIM58 forward, 5'-ATGAGGAAAGAGTTGGAGGACG-3' and reverse, 5'-AGCCACGATGCTTCTCAAACTC-3'.

Western blotting. A549 cells were collected and protein was extracted using RIPA lysis buffer (Abcam). The bbicinchoninic acid (BCA) kits were used to detect protein concentrations. The total protein ( $40 \mu \mathrm{g} /$ lane) was separated by $10 \%$ SDS-PAGE and transferred to nitrocellulose membrane. Subsequently, the membrane was incubated in a blocking solution (5\% skimmed milk) for $2 \mathrm{~h}$ at room temperature. The primary antibody was incubated with the samples at $4^{\circ} \mathrm{C}$ overnight and then the secondary antibody was incubated with the samples at room temperature for $2 \mathrm{~h}$. The primary antibodies used were as follows: GAPDH [cat. no. abs132004; 1: 3000; Absin (Shanghai) Biotechnology Co. Ltd.] and TRIM58 [cat. no. abs103739; 1: 1000; Absin (Shanghai) Biotechnology Co. Ltd.]. GAPDH was used as the loading control. Anti-rabbit IgG, HRP-linked Antibody [cat. no. 7074P2; 1: 1000; Cell Signaling Technology Inc.]. ECL luminescence reagent [cat. no. abs920; Absin (Shanghai) Biotechnology Co. Ltd.] was used for protein visualization.

Cell proliferation assay. A549 cells were seeded in 96-well plates and cell proliferation was detected with CellTiter 96 ${ }^{\circledR}$ AQueous One Solution Cell Proliferation Assay (MTS) (Promega Inc.). The absorbance value was measured at $490 \mathrm{~nm}$.Proliferation was tested every $24 \mathrm{~h}$ for 5 consecutive days. 
A

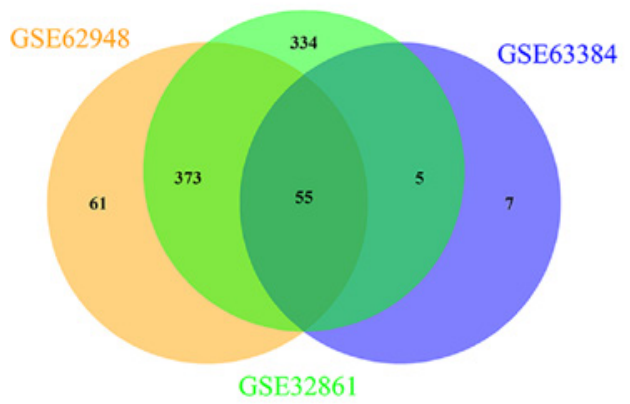

C

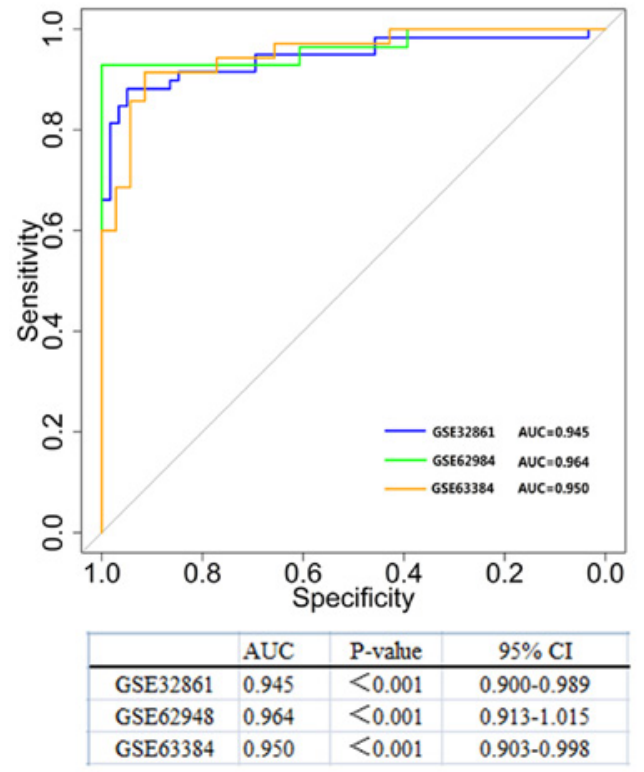

B

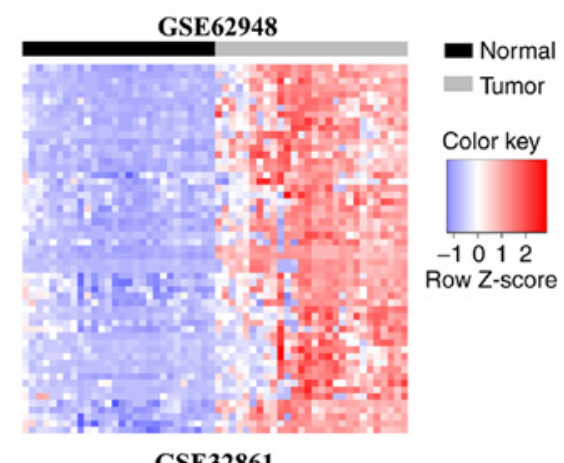

GSE32861

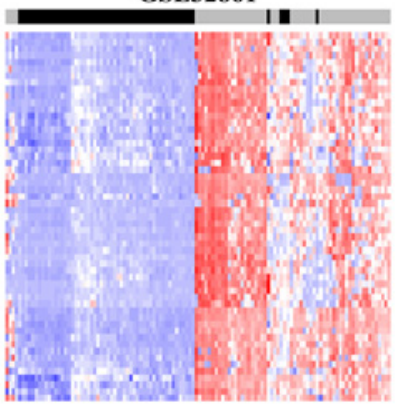

GSE63384

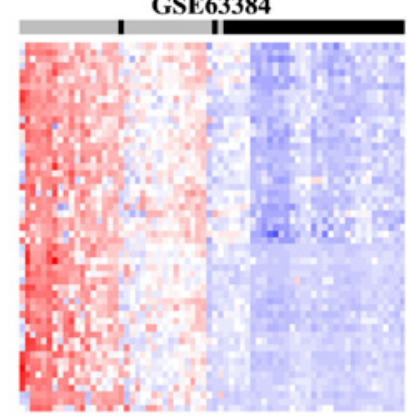

Figure 1. Identification of novel epigenetic signatures in lung cancer. (A) Identify differentially methylated probes through genome-wide DNA methylation analysis. Venn diagram showing that there are 55 common hypermethylated probes between the 3 LUAD datasets (GSE63384, GSE62948 and GSE32861). (B) Two-dimensional cluster analysis was performed on the differentially methylated probes in the 3 datasets. Each row is a probe; each column is a sample. The blue box, the expression level is low; the red box, the expression level is high. (C) Diagnostic value of TRIM58 methylation in lung cancer by ROC curves analysis. The blue line is GSE32861, the green line is GSE62948, and the orange line is GSE63384. ROC, receiver operating characteristic; TRIM58, tripartite motif containing 58; LUAD, lung adenocarcinoma; AUC, area under curve, CI, confidence interval.

Wound healing assay. A549 cells were seeded in 6-well plates $\left(4 \times 10^{5}\right.$ cells/well). When confluence exceeded $90 \%$, the cell monolayer was damaged with sterile pipette tips. Subsequently, the cells were washed gently and quickly with sterile PBS 3 times and then replaced with RPMI-1640 medium (Invitrogen; Thermo Fisher Scientific Inc.) containing 2\% FBS (Gibco; Themo Fisher Scientific Inc.) and incubated at $37^{\circ} \mathrm{C}$ for $48 \mathrm{~h}$. The cells in the scratch area were observed under a light microscope (magnification, x100) at 0 and $48 \mathrm{~h}$ respectively and the migration distance of cells at each time point was measured manually.

Transwell migration assay. Migration experiments were conducted using 24-well transwell chambers with 8- $\mu$ m aperture (Corning, Inc.).The A549 cells were collected, resuspended with serum-free RPMI-1640 medium and counted. The cell density was adjusted to $4 \times 10^{5}$ cells $/ \mathrm{ml}$. A total of $100 \mu \mathrm{l}$ cell suspension was inoculated into the upper chamber and $600 \mu \mathrm{l}$ RPMI-1640 medium containing 20\% FBS was added to the lower chamber. Cells were incubated at $37^{\circ} \mathrm{C}$ for $24 \mathrm{~h}$ and stained with $0.1 \%$ crystal violet for $20 \mathrm{~min}$ at room temperature. Under the light microscope (magnification, x100), a total of 3 fields were randomly selected for photographing and the number of migrated cells was counted manually.

Flow cytometry analysis. A549 cells were centrifuged at $300 \mathrm{x} \mathrm{g}$ for $5 \mathrm{~min}$ at room temperature and the cell precipitate was collected. Annexin V-FITC/propidium iodide (PI) Apoptosis detection kit (cat. no. V13241; Invitrogen; Thermo Fisher Scientific Inc.) was used to detect cell apoptosis (early apoptosis and late apoptosis) according to the manufacturer's protocol. Apoptotic analysis was implemented using flow cytometry (Cytomics FC500, Beckman Coulter, Inc.). CXP (Beckman Coulter, Inc.) software was used.

Gene set enrichment analysis, protein interaction and co-expression analysis. Gene set enrichment analysis (GSEA) (https://www.gsea-msigdb.org/gsea/index.jsp) was performed using mRNA expression data from the TCGA database. Patients were divided into high expression group and low 
Table I. Basic information of 55 differential methylation probes.

\begin{tabular}{|c|c|c|c|}
\hline $\begin{array}{l}\text { Ilmn ID } \\
\text { (Probes) }\end{array}$ & Gene Symbol & Genbank Accession & Annotation \\
\hline $\operatorname{cg} 08572611$ & ACTL6B & NM_016188.3 & Actin-like 6B \\
\hline $\operatorname{cg} 10235817$ & ADRA2C & NM_000683.3 & Adrenoceptor $\alpha 2 \mathrm{C}$ \\
\hline $\operatorname{cg} 17619823$ & ADRB3 & NM_000025.1 & Adrenoceptor $\beta 3$ \\
\hline $\operatorname{cg} 17525406$ & AJAP1 & NM_018836.2 & Adherens Junctions Associated Protein 1 \\
\hline $\operatorname{cg} 20959866$ & AJAP1 & NM_018836.2 & Adherens Junctions Associated Protein 1 \\
\hline $\operatorname{cg} 12111714$ & ATP8A2 & NM_016529.3 & ATPase Phospholipid Transporting 8A2 \\
\hline $\operatorname{cg} 05890484$ & BHMT & NM_001713.1 & Betaine-Homocysteine S-Methyltransferase \\
\hline $\operatorname{cg} 14419187$ & C2orf21 & NM_182587.1 & Unc-80 Homolog, NALCN Channel Complex Subunit \\
\hline $\operatorname{cg} 03544320$ & CRMP1 & NM_001313.3 & Collapsin Response Mediator Protein 1 \\
\hline $\operatorname{cg} 09229912$ & CUTL2 & NM_015267.1 & Cut Like Homeobox 2 \\
\hline $\operatorname{cg} 10303487$ & DPYS & NM_001385.1 & Dihydropyrimidinase \\
\hline $\operatorname{cg} 04048259$ & EDN3 & NM_000114.2 & Endothelin 3 \\
\hline $\operatorname{cg} 00027083$ & EPB41L3 & NM_012307.2 & Erythrocyte Membrane Protein Band 4.1 Like 3 \\
\hline $\operatorname{cg} 08575537$ & EPO & NM_000799.2 & Erythropoietin \\
\hline $\operatorname{cg} 20723355$ & FBXO39 & NM_153230.1 & F-Box Protein 39 \\
\hline $\operatorname{cg} 19831575$ & FGF4 & NM_002007.1 & Fibroblast Growth Factor 4 \\
\hline $\operatorname{cg} 02757432$ & GPR26 & NM_153442.1 & G Protein-Coupled Receptor 26 \\
\hline $\operatorname{cg} 06722633$ & GRIK3 & NM_000831.2 & Glutamate Ionotropic Receptor Kainate Type Subunit 3 \\
\hline $\operatorname{cg} 14859460$ & GRM6 & NM_000843.2 & Glutamate Metabotropic Receptor 6 \\
\hline $\operatorname{cg} 26609631$ & GSH1 & NM_145657.1 & GS Homeobox 1 \\
\hline $\operatorname{cg} 10883303$ & HOXA13 & NM_000522.2 & Homeobox A13 \\
\hline $\operatorname{cg} 26069745$ & HOXA2 & NM_006735.3 & Homeobox A2 \\
\hline $\operatorname{cg} 01354473$ & HOXA9 & NM_152739.2 & Homeobox A9 \\
\hline $\operatorname{cg} 01381846$ & HOXA9 & NM_152739.2 & Homeobox A9 \\
\hline $\operatorname{cg} 26521404$ & HOXA9 & NM_152739.2 & Homeobox A9 \\
\hline $\operatorname{cg} 06760035$ & HOXB4 & NM_024015.3 & Homeobox B4 \\
\hline $\operatorname{cg} 08089301$ & HOXB4 & NM_024015.3 & Homeobox B4 \\
\hline $\operatorname{cg} 23130254$ & HOXD12 & NM_021193.2 & Homeobox D12 \\
\hline $\operatorname{cg} 25574024$ & IGF2AS & NM_016412.1 & Insulin-Like Growth Factor II, Antisense \\
\hline $\operatorname{cg} 23349790$ & IGSF21 & NM_032880.2 & Immunoglobin Superfamily Member 21 \\
\hline $\operatorname{cg} 27409364$ & $\mathrm{KCNC} 1$ & NM_004976.2 & Potassium Voltage-Gated Channel Subfamily C Member 1 \\
\hline $\operatorname{cg} 22660578$ & LHX1 & NM_005568.2 & LIM homeobox protein 1 \\
\hline $\operatorname{cg} 04330449$ & NEUROG1 & NT_034772.5 & Neurogenin 1 \\
\hline $\operatorname{cg} 22881914$ & NID2 & NM_007361.2 & Nidogen 2 \\
\hline $\operatorname{cg} 08441806$ & NKX6-2 & NM_177400.1 & NK6 Transcription Factor Related, Locus 2 \\
\hline $\operatorname{cg} 24194775$ & NPR2 & NM_000907.2 & Natriuretic Peptide Receptor 2 \\
\hline $\operatorname{cg} 00548268$ & NPTX2 & NM_002523.1 & Neuronal Pentraxin 2 \\
\hline $\operatorname{cg} 12799895$ & NPTX2 & NM_002523.1 & Neuronal Pentraxin 2 \\
\hline $\operatorname{cg} 20291049$ & POU3F3 & NM_006236.1 & POU Domain Class 3, Transcription Factor 3 \\
\hline $\operatorname{cg} 12374721$ & PRAC & NM_032391.2 & PRAC1 Small Nuclear Protein \\
\hline $\operatorname{cg} 09516965$ & PTGDR & NM_000953.2 & Prostaglandin D2 Receptor \\
\hline $\operatorname{cg} 08118311$ & SALL3 & NM_171999.1 & Spalt Like Transcription Factor 3 \\
\hline $\operatorname{cg} 15191648$ & SALL3 & NM_171999.1 & Spalt Like Transcription Factor 3 \\
\hline $\operatorname{cg} 02919422$ & SOX17 & NM_022454.2 & SRY-Box Transcription Factor 17 \\
\hline cg02164046 & SST & NM_001048.3 & Somatostatin \\
\hline $\operatorname{cg} 17586860$ & SSTR4 & NM_001052.1 & Somatostatin Receptor 4 \\
\hline $\operatorname{cg} 25720804$ & TLX3 & NM_021025.2 & T Cell Leukemia Homeobox 3 \\
\hline $\operatorname{cg} 14696396$ & TM6SF1 & NM_023003.1 & Transmembrane 6 Superfamily Member 1 \\
\hline $\operatorname{cg} 01009664$ & $\mathrm{TRH}$ & NM_007117.1 & Thyrotropin Releasing Hormone \\
\hline $\operatorname{cg} 07533148$ & TRIM58 & NM_015431.2 & Tripartite Motif Containing 58 \\
\hline $\operatorname{cg} 07307078$ & TUBB6 & NM_032525.1 & Tubulin $\beta 6$ \\
\hline $\operatorname{cg} 20616414$ & WNK2 & NM_006648.3 & WNK Lysine Deficient Protein Kinase 2 \\
\hline $\operatorname{cg} 16638540$ & ZNF135 & NM_003436.2 & Zinc Finger Protein 135 \\
\hline $\operatorname{cg} 03975694$ & ZNF540 & NM_152606.2 & Zinc Finger Protein 540 \\
\hline $\operatorname{cg} 16731240$ & ZNF577 & NM_032679.1 & Zinc Finger Protein 577 \\
\hline
\end{tabular}


A

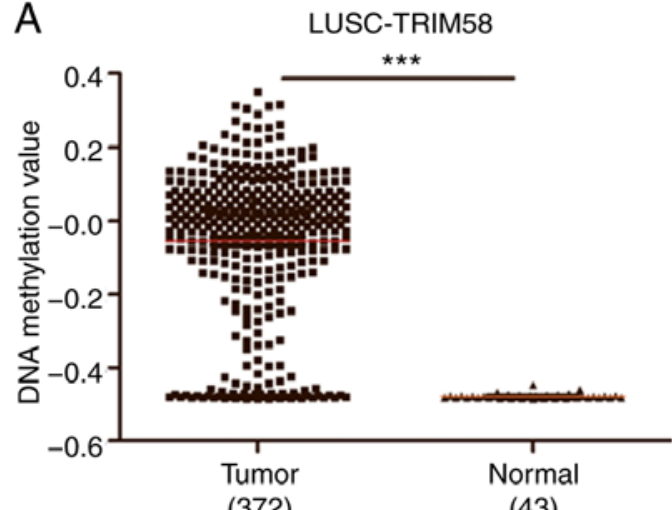

(372)

B

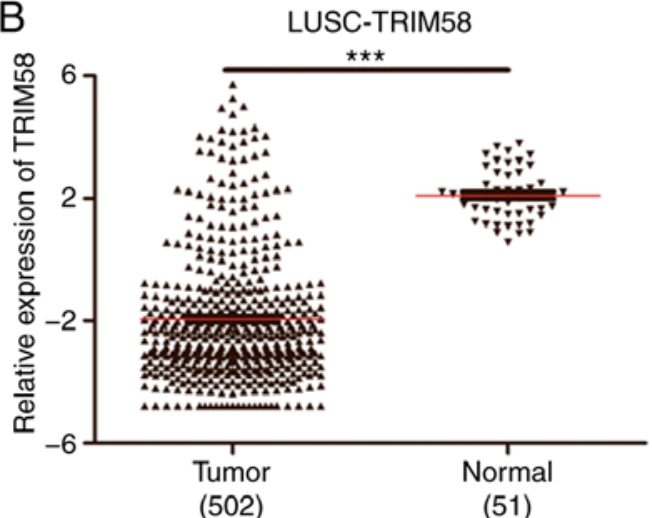

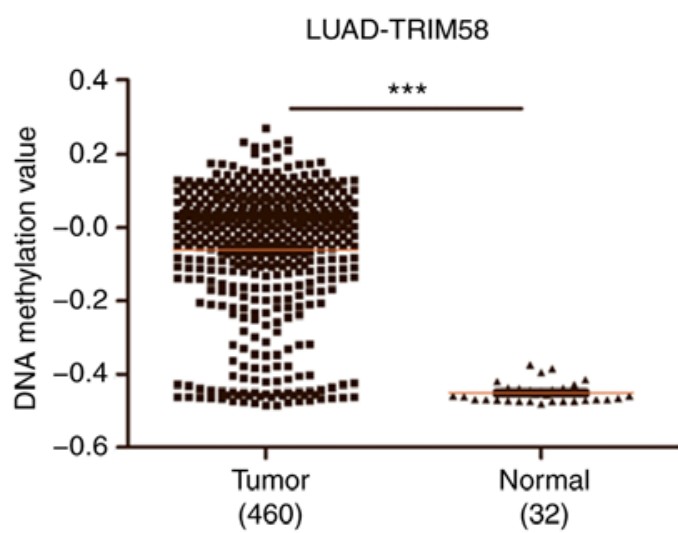

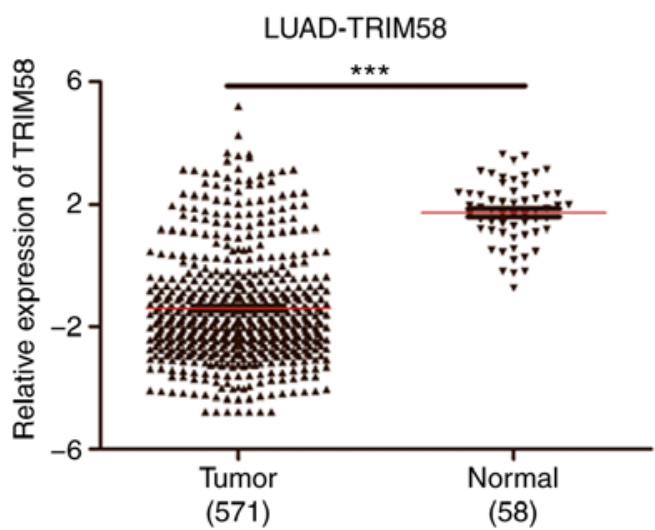

(571)
(58)

C

\section{LUSC}
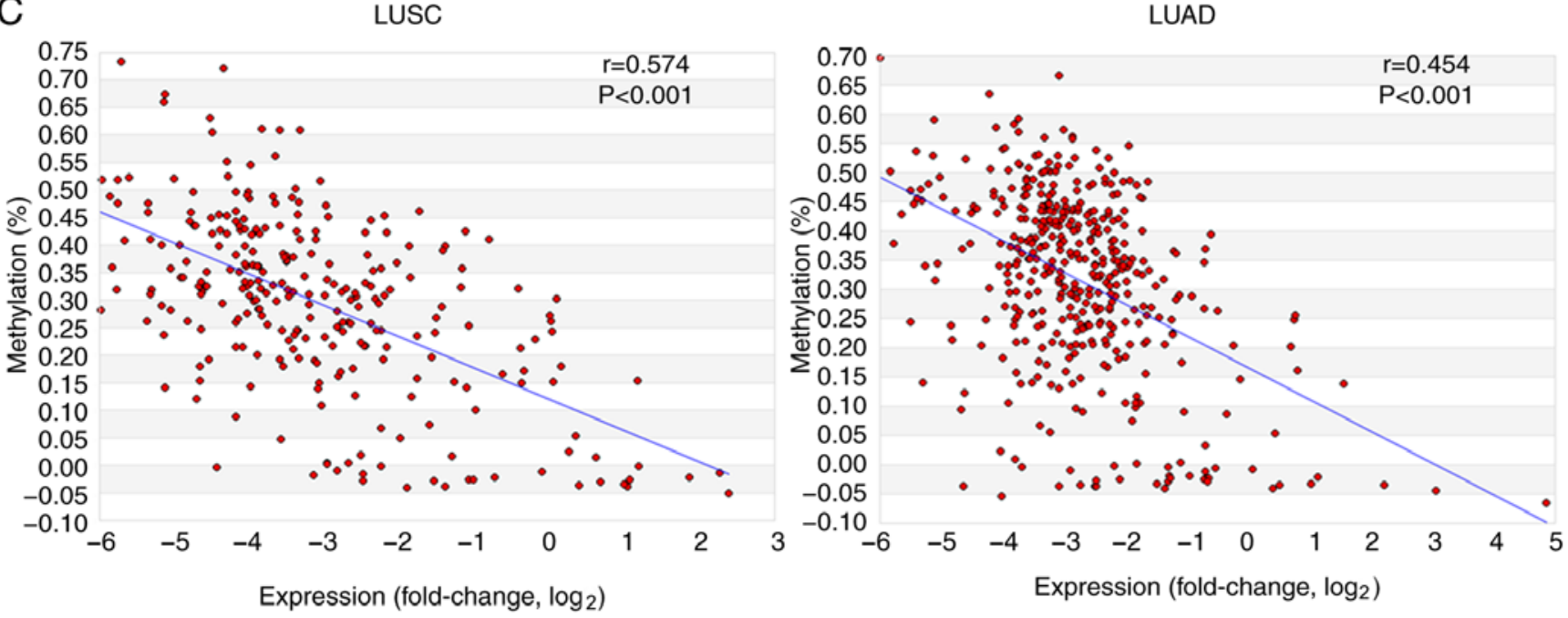

Figure 2. TRIM58 is coordinately hypermethylated and downregulated in lung cancer. (A) Methylation levels of TRIM58 were verified in LUSC and LUAD, respectively. (B) TRIM58 expression was verified in LUSC and LUAD, respectively. (C) Correlation analysis between DNA methylation and gene expression. $\mathrm{X}$-axis, mRNA expression level, Y-axis, DNA methylation level and $\mathrm{r}$, Spearmen correlation coefficient. ${ }^{* * *} \mathrm{P}<0.001$. TRIM58, tripartite motif containing 58; LUAD, lung adenocarcinoma; LUSC, lung squamous cell carcinoma.

expression group according to the median expression value $\left(\right.$ LUAD $_{\text {median }}=-1.966$, LUSC $\left._{\text {median }}=-2.457\right)$. Protein-Protein Interaction Network analysis was constructed using the STRING database (https://string-db.org/). Co-expression analysis was performed on lung cancer samples from the Oncomine database (https://www.oncomine.org/).

Statistical analysis. SPSS version 18.0 (SPSS Inc.) and GraphPad Prism 5.0 software (GraphPad, Inc.) were used for statistical analysis. All data was from 3 experimental replicates and presented as the mean \pm SEM. Independent Student's t-test was applied to the comparisons between groups. Spearman correlation method was used to identify the correlation between DNA methylation and mRNA expression. ROC analysis was used to explore the diagnostic value of TRIM58. $\mathrm{P}<0.05$ was considered to indicate statistical significance.

\section{Results}

Identification of novel epigenetic signatures in lung cancer. In the present study, 3 LUAD methylation profiles (GSE63384, GSE62948, and GSE32861) were collected from the GEO 
A
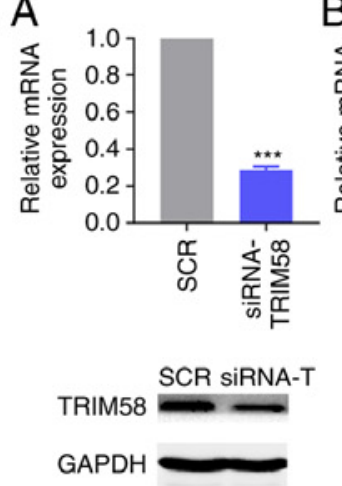

B

E

$\mathrm{Oh}$

$48 \mathrm{~h}$
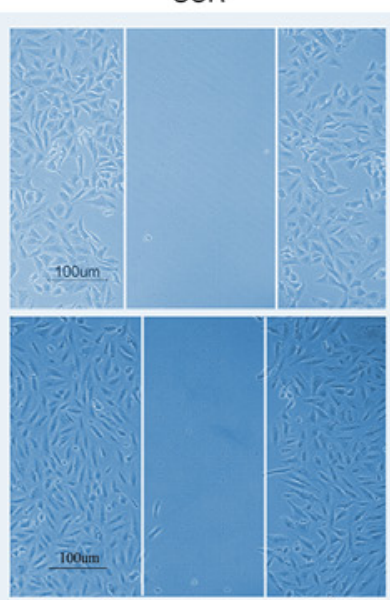

G

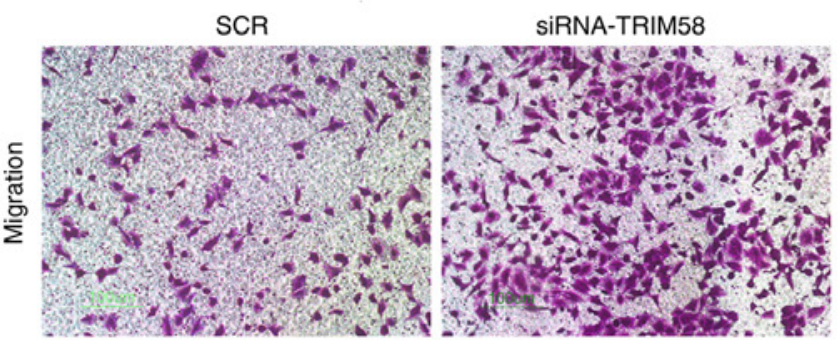

SiRNA-TRIM58
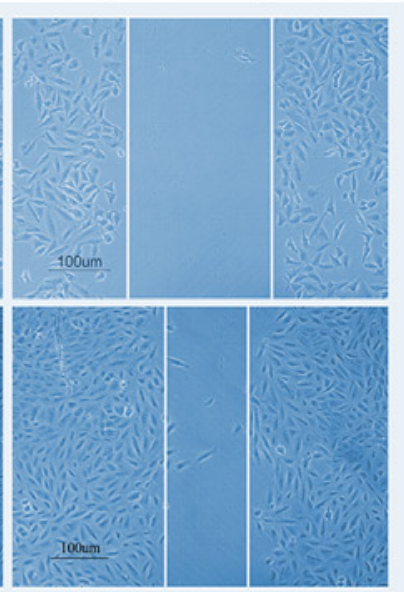

Vector pcDNA3.1-T
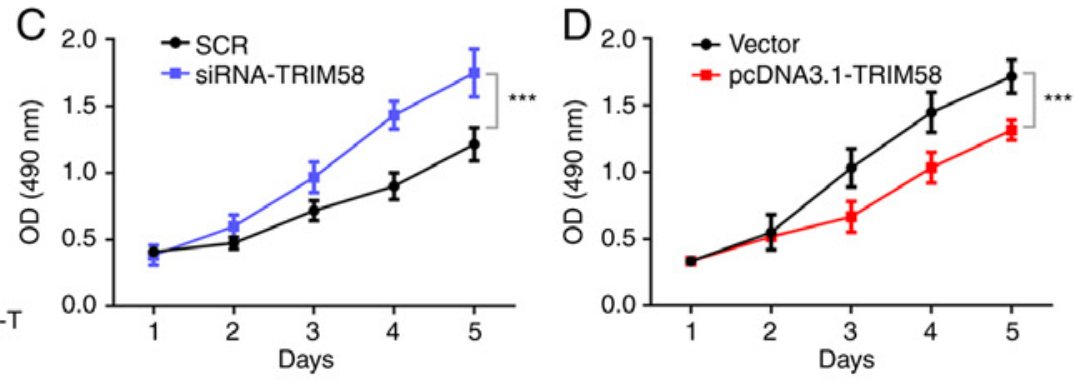

$\mathrm{F}$

Vector

PCDNA3.1-TRIM58

$\mathrm{Oh}$
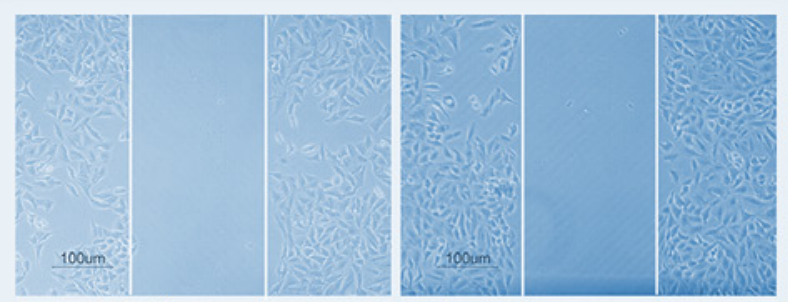

$48 \mathrm{~h}$
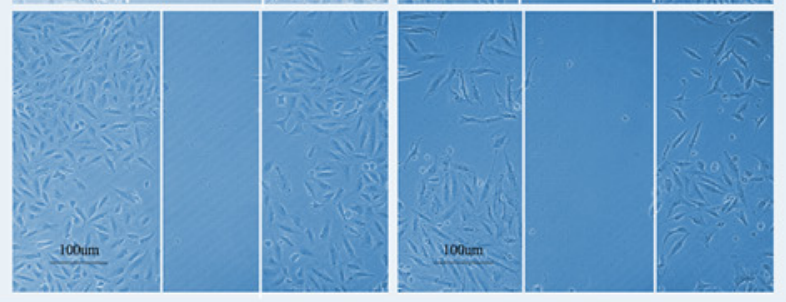

$\mathrm{H}$
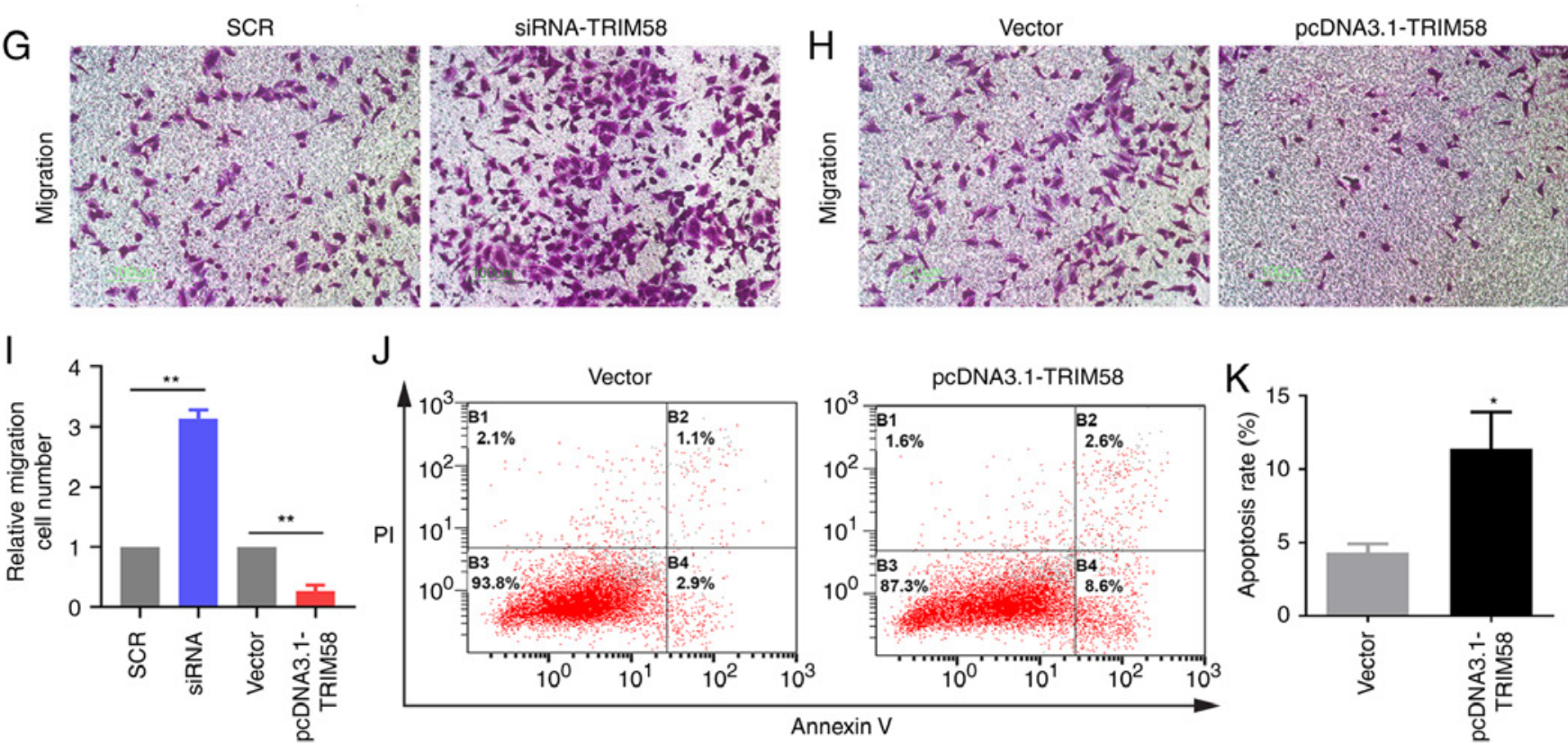

$\mathrm{J}$
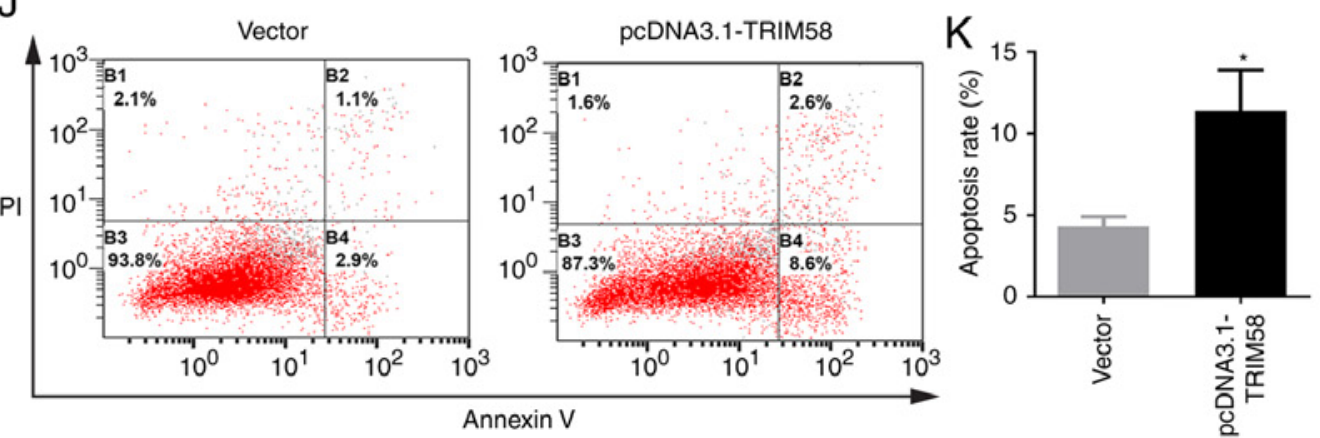

Figure 3. TRIM58 inhibits the malignant phenotypes of lung cancer cells. To evaluate the molecular functions of TRIM58 in lung cancer, loss-of-function and gain-of-function assays were conducted in A549 cell line. A series of transfection experiments were performed. (A and B) siRNA and plasmids effectively regulated the expression of TRIM58 in the A549 cell line. mRNA and protein expression of TRIM58 were detected by RT-qPCR and western blotting, respectively. (C and D) MTS assay was used to assess cell proliferation. Cell migration was assessed using the (E and F) wound healing assay and (G, H and I) transwell assay. ( $\mathrm{J}$ and $\mathrm{K}$ ) Flow cytometry was used to verify cell apoptosis. ${ }^{*} \mathrm{P}<0.05,{ }^{* * *} \mathrm{P}<0.01$ and ${ }^{* * *} \mathrm{P}<0.001$. SCR, scrambled negative control; si, small interfering; vector, pcDNA3.1; PI, propidium iodide; TRIM58, tripartite motif containing 58; OD, optical density. All these experiments are compared between the experimental group and the control group.

database to identify DMGs between tumors and NTL tissues. The present study focused on probes that were specifically hypermethylated in tumors. The results demonstrated that
67 probes were hypermethylated in GSE63384, 489 probes were hypermethylated in GSE62948 and 767 probes were hypermethylated in GSE32861 (Fig. 1A). Subsequently, an 
A

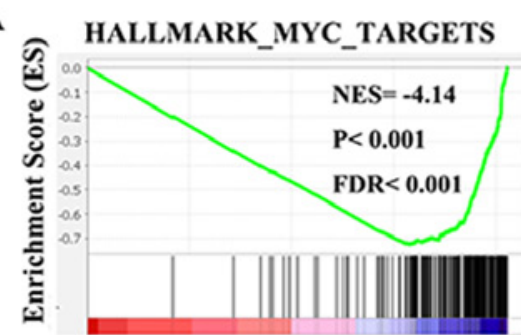

TRIM58-High

TRIM58-Low
B

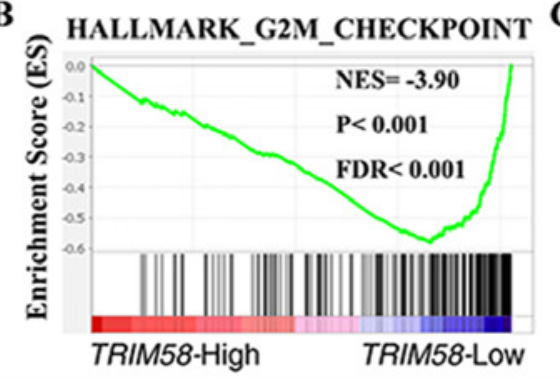

HALLMARK_MTORC1_SIGNALING

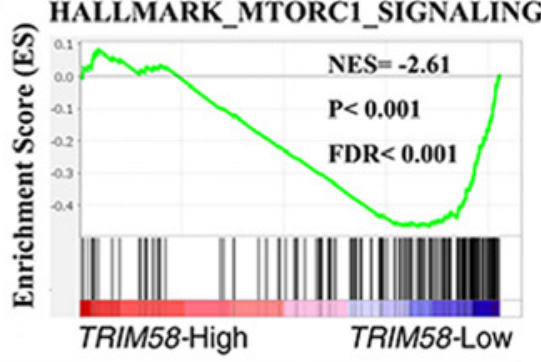

LUSC

D

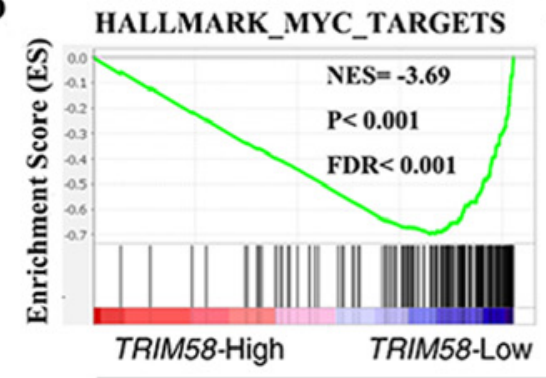

E

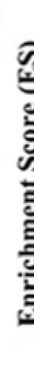

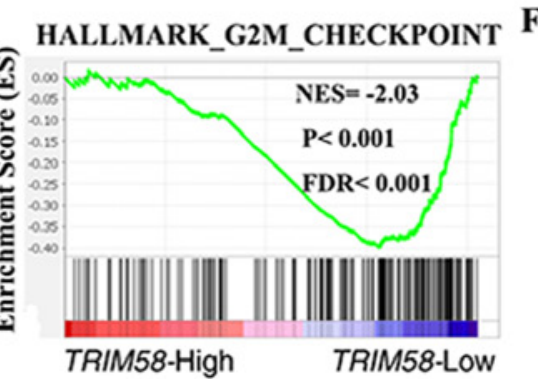

LUAD

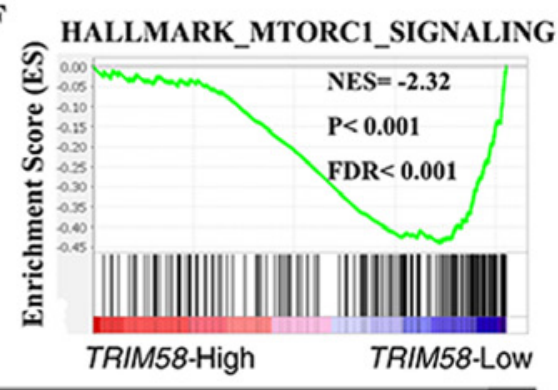

Figure 4. Identification of TRIM58-associated signaling pathway in lung cancer. GSEA demonstrated that TRIM58 was negatively associated with (A and D) MYC targets, (B and E) G2M checkpoints (C, and F) mTORC1 signaling pathway in LUSC and LUAD, respectively. TRIM58, tripartite motif containing 58; LUAD, lung adenocarcinoma; LUSC, lung squamous cell carcinoma; FDR, false discovery rate; mTORC1, mechanistic target of rapamycin complex 1; NES, normalized enrichment score.

overlapping analysis of these DMGs was conducted and 55 probes that were significantly hypermethylated in the 3 lung cancer datasets were found (Fig. 1A and Table I). Additionally, the 55 probes were analyzed by two-dimensional hierarchical cluster analysis, which could clearly distinguish tumor tissues from NTL tissues (Fig. 1B). These results revealed a series of probes that are hypermethylated in LUAD.

TRIM58 serves as a potential diagnostic biomarker for lung cancer. ROC analysis was used to evaluate the diagnostic value of TRIM58 in lung cancer. The area under the curve (AUC) values of the tumor and NTL groups in the TRIM58 analyses were significant for all 3 lung cancer datasets and were as follows: $\mathrm{AUC}_{\mathrm{GSE} 63384}=0.950[\mathrm{P}<0.001 ; 95 \%$ confidence interval (CI), 0.903-0.998]; $\mathrm{AUC}_{\mathrm{GSE} 62948}=0.964$ $(\mathrm{P}<0.001 ; 95 \% \mathrm{CI}, 0.913-1.015)$ and $\mathrm{AUC}_{\mathrm{GSE} 32861}=0.945$ $(\mathrm{P}<0.001 ; 95 \% \mathrm{CI}, 0.900-0.989)$ (Fig. 1C). The aforementioned results demonstrated that the methylation level of TRIM58 can distinguish tumor tissues from normal tissues and that TRIM58 methylation is a potential marker for the early diagnosis of lung cancer.

TRIM58 is coordinately hypermethylated and downregulated in lung cancer. The present study reviewed a large amount of literature on these 55 hypermethylated probes. Among them, TRIM58 is a member of the TRIM family, which is located on chromosome 1 and on $\mathrm{CpG}$ islands (36). Previous studies have shown that TRIM protein may serve an important role in tumorigenesis; however, the mechanism by which TRIM58 participates in the regulation of lung cancer remains unclear $(17,37)$.
Firstly, the results of high-throughput screening were validated using the TCGA datasets. A total of 372 LUSC samples with 43 NTL samples and 460 LUAD samples with 32 NTL samples were used for independent verification. In both, LUSC and LUAD, TRIM58 was hypermethylated in tumor tissues compared to normal tissues (Fig. 2A). In contrast, TRIM58 was downregulated in both LUSC and LUAD compared to normal tissue (Fig. 2B). TRIM58 was coordinately hypermethylated and downregulated in lung tumors compared to normal tissue, indicating that it may be a potential tumor suppressor gene. Subsequently, the correlation between DNA methylation and mRNA expression was analyzed in the MethHC database. Scatter plot analysis revealed that the DNA methylation and mRNA expression levels of TRIM58 were negatively correlated and the Spearman correlation coefficient values were $\mathrm{r}_{\text {LUSC }}=0.574$ and $\mathrm{r}_{\text {LUAD }}=0.454$ (both $\mathrm{P}<0.001$; Fig. $2 \mathrm{C}$ ). These results suggested that TRIM58 expression may be regulated by epigenetics, DNA methylation in particular.

TRIM58 inhibits the malignant phenotypes of lung cancer cells. To evaluate the molecular functions of TRIM58 in lung cancer, loss-of-function and gain-of-function assays were conducted with the A549 cell line. The effects of silencing and overexpressing TRIM58 on the malignant phenotype were detected. Firstly, the expression of TRIM58 in A549 cells was silenced using siRNA. siRNA-TRIM58 was constructed using scramble siRNA as a negative control (Fig. 3A). The results demonstrated that compared with the control group, the siRNA-TRIM58 group exhibited significantly downregulated expression of TRIM58 (Fig. 3A). The MTS assay indicated that the silencing of TRIM58 promoted the proliferation 


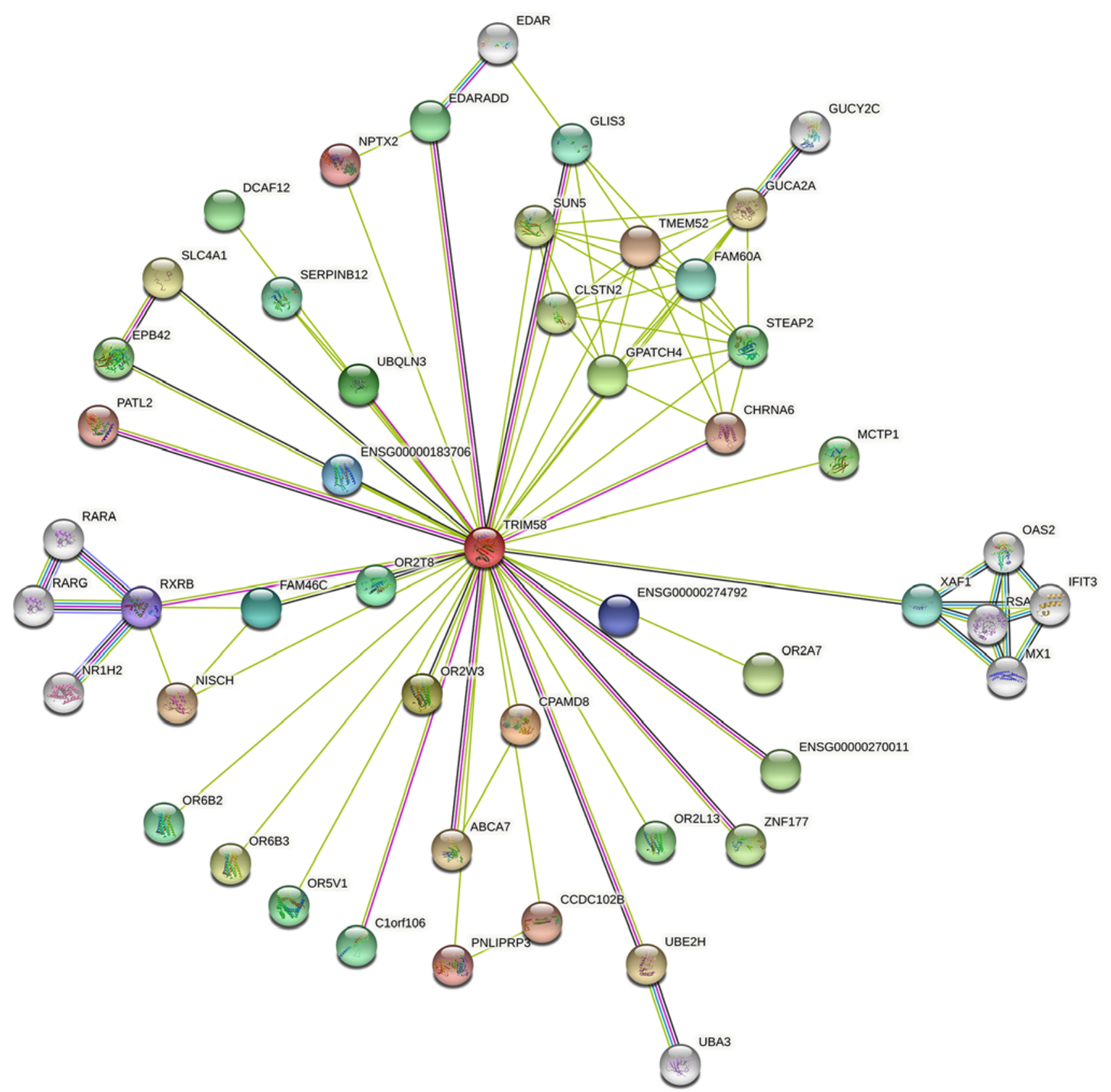

Figure 5. Protein-Protein Interaction network analysis. Using the STRING database, a series of proteins interacting with TRIM58 were identified. The minimum interaction score for this network is 0.4 .

of lung cancer cells (Fig. 3C). An overexpression vector TRIM58-pcDNA3.1 was constructed in the present study and an empty pcDNA3.1 vector was used as a negative control. The expression level of pcDNA3.1-TRIM58 was significantly increased compared with that of the vector (control group) (Fig. 3B). TRIM58 overexpression inhibited cell proliferation (Fig. 3D). Subsequently, wound-healing and transwell assays were used to evaluate cell migration. Compared with the control group (scramble siRNA), TRIM58 silencing potently accelerated the migration of lung cancer cells (Fig. 3E, G and I), whereas overexpression of TRIM58 exerted the opposite effect (Fig. 3F, $\mathrm{H}$ and I). In addition, flow cytometry analysis demonstrated that TRIM58 overexpression promoted the apoptosis of lung cancer cells compared with empty pcDNA3.1 vector (Fig. 3J and K). In summary, the overexpression of TRIM58, a potential tumor suppressor gene inhibited cell proliferation and migration and promoted cell apoptosis.

Identification of TRIM58-associated signaling pathways in lung cancer. To explore the molecular mechanisms by which TRIM58 contributes to lung cancer progression, GSEA was performed using mRNA expression data from the TCGA database. Several classic mechanisms of carcinogenesis, such as MYC targets $[\mathrm{P}<0.001$; false discovery rate $(\mathrm{FDR})<0.001 ; \mathrm{NES}_{\mathrm{LUSC}}=-4.14 ; \mathrm{P}<0.001 ; \mathrm{FDR}<0.001$; $\mathrm{NES}_{\mathrm{LUAD}}=-3.69$ ] (Fig. 4A and D) and $\mathrm{G} 2 \mathrm{M}$ checkpoint-related genes $\left(\mathrm{P}<0.001 ; \mathrm{FDR}<0.001 ; \mathrm{NES}_{\mathrm{LUSC}}=-3.90 ; \mathrm{P}<0.001\right.$; $\mathrm{FDR}<0.001$; $\mathrm{NES}_{\mathrm{LUAD}}=-2.03$ ) (Fig. 4B and $\mathrm{E}$ ), were enriched in samples with low TRIM58 expression. It was also observed that TRIM58 was negatively correlated with the mTORC1 


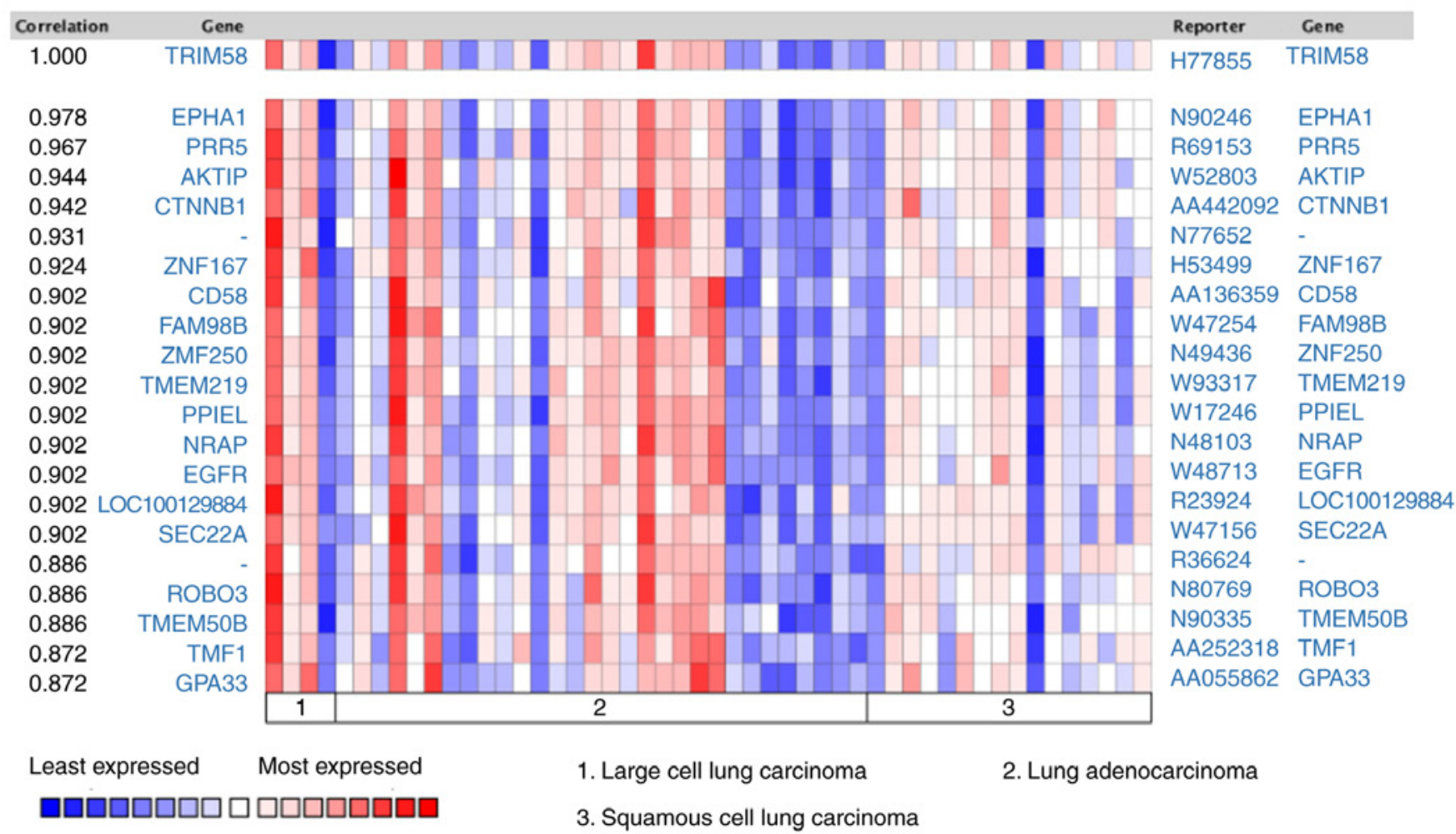

Figure 6. Co-expression analysis. The TRIM58 co-expression gene profile was identified by Oncomine. Blue squares represent least expressed, red squares represent most expressed.

signaling pathway $\left(\mathrm{P}<0.001 ; \mathrm{FDR}<0.001 ; \mathrm{NES}_{\mathrm{LuSC}}=-2.61\right.$; $\mathrm{P}<0.001 ; \mathrm{FDR}<0.001 ; \mathrm{NES}_{\mathrm{LUAD}}=-2.32$ ) (Fig. $4 \mathrm{C}$ and F), further indicating a tumor suppressor role of TRIM58.

Protein interaction and co-expression analysis. Protein-Protein Interaction Network analysis was constructed using the STRING database (Fig. 5). A series of proteins interacting with TRIM58 were identified, such as CPAMD8 (C3 and PZP-like alpha-2-macroglobulin domain-containing protein 8), OR2W3 (Olfactory Receptor Family 2 Subfamily W Member 3), GPATCH4 (G Patch Domain-Containing Protein 4), UBQLN3 (Ubiquilin 3), OR2T8 (Olfactory Receptor Family 2 Subfamily T Member 8), FAM46C (Family with sequence similarity 46 member C) and RXRB (Retinoid $\mathrm{X}$ Receptor Beta). Subsequently, co-expression analysis was performed on lung cancer samples from the Oncomine database. Tomida et al (38) revealed that EPHA1 (EPH Receptor A1) $(\mathrm{r}=0.978)$, PRR5 (Proline-Rich Protein 5) $(\mathrm{r}=0.967)$, AKTIP (AKT Interacting Protein) $(\mathrm{r}=0.944), \mathrm{CTNNB1}$ (Catenin $\beta-1)$ $(\mathrm{r}=0.942)$, ZNF167 (Zinc Finger Protein 167) ( $\mathrm{r}=0.924)$, CD58 (CD58 Antigen) ( $r=0.902)$, FAM98B (Family With Sequence Similarity 98 Member B) $(r=0.902)$, ZNF250 (Zinc Finger Protein 250) $(\mathrm{r}=0.902)$, TMEM219 (Transmembrane Protein 219) ( $\mathrm{r}=0.902)$ were co-expressed with TRIM58 (Fig. 6). These results suggested that TRIM58 closely interacts with numerous functional genes involved in lung cancer.

\section{Discussion}

Previous studies have shown that epigenetic changes can be used as biomarkers for the detection of malignant tumors, such as hypermethylation of GSTP1 (Glutathione S-Transferase Pi 1) in prostate cancer $(8,39)$. Abnormal hypermethylation in the promoter region of tumor suppressor gene RASSF1A (RAS associated domain family $1 \mathrm{~A}$ ), repair gene MGMT, apoptosis-related genes EBF3 (Early B Cell Factor 3), cell cycle-related gene CDKN2B (Cyclin-dependent kinase inhibitor 2B) and other important genes often occurs in precancerous lesions or during the early carcinogenesis of tumors, inhibiting transcriptional activity and leading to tumor occurrence (40-42). Additionally, abnormal genome-wide hypomethylation resulting in genomic instability and oncogene activation can induce tumors (43).

DNA methylation is an early event occurring in tumors, providing a stable signal with high sensitivity and specificity (44). In the present study, high-throughput screening and independent validation demonstrated that TRIM58 was hypermethylated and downregulated in lung cancer compared to normal tissues. ROC analysis performed in the present study revealed that TRIM58 had a strong predictive value for the early diagnosis of lung cancer.

TRIM family proteins serve an important role in tumorigenesis (17). There are few reports of the molecular mechanism of TRIM58's regulatory role in lung cancer. The morbidity and mortality of lung cancer is very high and tumor metastasis is an important cause of treatment failure and death (5). In vitro and in vivo experiments (45) demonstrated that TRIM62 inhibits the metastasis of cervical cancer by inhibiting the c-Jun/Slug signaling pathway. Chen et al (46) demonstrated that TRIM62 as an oncogene, negatively regulates TGF- $\beta$-mediated epithelial mesenchymal transition, hence inhibiting tumor invasion and metastasis. As a member 
of the same subfamily of TRIM62 (C-IV-1), it was hypothesized that TRIM58 may regulate the malignant phenotype of cancer. To further evaluate the molecular functions of TRIM58 in lung cancer, loss-of-function and gain-of-function assays were conducted in the present study in lung cancer cells (A549 cells). The results indicated that TRIM58 was a novel tumor suppressor gene in lung cancer.

In addition, the present study attempted to explore the signaling pathways related to TRIM58 in lung cancer to understand the potential mechanisms by which TRM58 participates in the regulation of tumor progression. Gene set enrichment analysis revealed that TRIM58 expression was negatively correlated with MYC targets, G2M checkpoints and the mTORC1 (mechanistic target of rapamycin complex 1) signaling pathway. mTOR is a protein kinase that can regulate a large number of cellular processes, such as cell growth, proliferation and differentiation through the $\mathrm{PI} 3 \mathrm{~K} / \mathrm{AKT} / \mathrm{mTOR}$ pathway (47). Among mTOR proteins, $\mathrm{mTORC1}$ is frequently activated in human cancers and targeting mTORC1 signaling is a promising strategy for tumor therapy (48). In addition, MYC and $\mathrm{G} 2 \mathrm{M}$ checkpoints are classic tumor-promoting signaling pathways (49). Hence, the results of the present study indicate that TRIM58 may serve an anticancer role by inhibiting the signaling pathways of mTORC1.

In conclusion, through DNA methylation-based profiling screening, the present study demonstrated that TRIM58 methylation has promise as a biomarker for the early diagnosis of lung cancer. Cell experiments confirmed the role of TRIM58 as a tumor suppressor gene in lung cancer and overexpression of TRIM58 inhibited the malignant phenotype of tumors. Gene set enrichment analysis revealed that TRIM58 expression was negatively correlated with the mTORC1 signaling pathway. Future studies are needed to further explore the specific regulatory mechanisms to provide new targets for the early diagnosis and effective treatment of lung cancer.

\section{Acknowledgements}

The author would like to thank Professor Sheng Deqiao (China Three Gorges University, Yichang, China) for guidance and help with the experiments.

\section{Funding}

This work was supported by the Scientific Research Project of Hunan Provincial Health Commission (grant no. 202103021291) and Natural Science Foundation of Hubei Province of China (grant no. 2018CFB142).

\section{Availability of data and materials}

The datasets used and/or analyzed during the current study are available from the corresponding author on reasonable request.

\section{Author contributions}

YXS performed the experiments, analyzed the data and prepared the manuscript. YXS confirmed the authenticity of all the raw data. The author has read and approved the final manuscript.

\section{Ethics approval and consent to participate}

Not applicable.

\section{Patient consent for publication}

Not applicable.

\section{Competing interests}

The author declares that he has no competing interests.

\section{References}

1. Siegel RL, Miller KD, Fuchs HE and Jemal A: Cancer statistics, 2021. CA Cancer J Clin 71: 7-33, 2021.

2. Cao M and Chen W: Epidemiology of lung cancer in China. Thorac Cancer 10: 3-7, 2019.

3. McIntyre A and Ganti AK: Lung cancer-A global perspective. J Surg Oncol 115: 550-554, 2017.

4. Liloglou T, Bediaga NG, Brown BR, Field JK and Davies MP: Epigenetic biomarkers in lung cancer. Cancer Lett 342: 200-212, 2014.

5. Wood SL, Pernemalm M, Crosbie PA and Whetton AD: The role of the tumor-microenvironment in lung cancer-metastasis and its relationship to potential therapeutic targets. Cancer Treat Rev 40: 558-566, 2014.

6. Visconti R, Morra F, Guggino G and Celetti A: The between now and then of lung cancer chemotherapy and immunotherapy. Int J Mol Sci 18: E1374, 2017.

7. Shi YX, Yin JY, Shen Y, Zhang W, Zhou HH and Liu ZQ: Genome-scale analysis identifies NEK2, DLGAP5 and ECT2 as promising diagnostic and prognostic biomarkers in human lung cancer. Sci Rep 7: 8072, 2017.

8. Michalak EM, Burr ML, Bannister AJ and Dawson MA: The roles of DNA, RNA and histone methylation in ageing and cancer. Nat Rev Mol Cell Biol 20: 573-589, 2019.

9. Jones PA and Baylin SB: The fundamental role of epigenetic events in cancer. Nat Rev Genet 3: 415-428, 2002.

10. Dawson MA and Kouzarides T: Cancer epigenetics: From mechanism to therapy. Cell 150: 12-27, 2012.

11. Seijo LM, Peled N, Ajona D, Boeri M, Field JK, Sozzi G, Pio R, Zulueta JJ, Spira A, Massion PP, et al: Biomarkers in lung cancer screening: achievements, promises, and challenges. J Thorac Oncol 14: 343-357, 2019.

12. Choo KB: Epigenetics in disease and cancer. Malays J Pathol 33: 61-70, 2011.

13. Schübeler D: Function and information content of DNA methylation. Nature 517: 321-326, 2015.

14. Shinjo K and Kondo Y: Targeting cancer epigenetics: Linking basic biology to clinical medicine. Adv Drug Deliv Rev 95: 56-64, 2015.

15. Jones PA, Issa JPJ and Baylin S: Targeting the cancer epigenome for therapy. Nat Rev Genet 17: 630-641, 2016.

16. Schiffmann I, Greve G, Jung M and Lübbert M: Epigenetic therapy approaches in non-small cell lung cancer: Update and perspectives. Epigenetics 11: 858-870, 2016.

17. Hatakeyama S: TRIM family proteins: Roles in autophagy, immunity, and carcinogenesis. Trends Biochem Sci 42: 297-311, 2017.

18. Hatakeyama S: TRIM proteins and cancer. Nat Rev Cancer 11: 792-804, 2011.

19. Napolitano LM and Meroni G: TRIM family: Pleiotropy and diversification through homomultimer and heteromultimer formation. IUBMB Life 64: 64-71, 2012.

20. Wang S, Zhang Y, Huang J, Wong CC, Zhai J, Li C, Wei G, Zhao L, Wang G, Wei H, et al: TRIM67 activates p53 to suppress colorectal cancer initiation and progression. Cancer Res 79: 4086-4098, 2019.

21. Cambiaghi V, Giuliani V, Lombardi S, Marinelli C, Toffalorio F and Pelicci PG: TRIM proteins in cancer. Adv Exp Med Biol 770: 77-91, 2012.

22. Meroni G and Diez-Roux G: TRIM/RBCC, a novel class of 'single protein RING finger' E3 ubiquitin ligases. BioEssays 27: 1147-1157, 2005. 
23. Reymond A, Meroni G, Fantozzi A, Merla G, Cairo S, Luzi L, Riganelli D, Zanaria E, Messali S, Cainarca S, et al: The tripartite motif family identifies cell compartments. EMBO J 20 : 2140-2151, 2001

24. Short KM and Cox TC: Subclassification of the RBCC/TRIM superfamily reveals a novel motif necessary for microtubule binding. J Biol Chem 281: 8970-8980, 2006.

25. Herbst RS, Morgensztern D and Boshoff C: The biology and management of non-small cell lung cancer. Nature 553: 446-454, 2018.

26. Shi YX, Wang Y, Li X, Zhang W, Zhou HH, Yin JY and Liu ZQ: Genome-wide DNA methylation profiling reveals novel epigenetic signatures in squamous cell lung cancer. BMC Genomics 18: 901, 2017.

27. Robles AI, Arai E, Mathé EA, Okayama H, Schetter AJ, Brown D, Petersen D, Bowman ED, Noro R, Welsh JA, et al: An integrated prognostic classifier for stage I lung adenocarcinoma based on mRNA, microRNA, and DNA methylation biomarkers. J Thorac Oncol 10: 1037-1048, 2015

28. Mansfield AS, Wang L, Cunningham JM, Jen J, Kolbert CP, Sun $\mathrm{Z}$ and Yang P: DNA methylation and RNA expression profiles in lung adenocarcinomas of never-smokers. Cancer Genet 208: 253-260, 2015.

29. Selamat SA, Chung BS, Girard L, Zhang W, Zhang Y, Campan M, Siegmund KD, Koss MN, Hagen JA, Lam WL, et al: Genome-scale analysis of DNA methylation in lung adenocarcinoma and integration with mRNA expression. Genome Res 22 $1197-1211,2012$

30. Gentleman RC, Carey VJ, Bates DM, Bolstad B, Dettling M, Dudoit S, Ellis B, Gautier L, Ge Y, Gentry J, et al: Bioconductor: Open software development for computational biology and bioinformatics. Genome Biol 5: R80, 2004.

31. Smyth GK: limma: Linear models for microarray data. In: Bioinformatics and Computational Biology Solutions Using R and Bioconductor. pp397-420, Springer, New York, NY, 2005.

32. Ghosh D: Incorporating the empirical null hypothesis into the Benjamini-Hochberg procedure. Stat Appl Genet Mol Biol 11: /j/sagmb.2012.11.issue-4/1544-6115.1735/1544-6115.1735.xml, 2012. doi: $10.1515 / 1544-6115.1735$

33. Goldman M, Craft B, Swatloski T, Cline M, Morozova O, Diekhans M, Haussler D and Zhu J: The UCSC Cancer Genomics Browser: Update 2015. Nucleic Acids Res 43: D812-D817, 2015.

34. Huang WY, Hsu SD, Huang HY, Sun YM, Chou CH, Weng SL and Huang HD: MethHC: A database of DNA methylation and gene expression in human cancer. Nucleic Acids Res 43 D856-D861, 2015.

35. Livak KJ and Schmittgen TD: Analysis of relative gene expression data using real-time quantitative PCR and the 2(-Delta Delta C(T)) Method. Methods 25: 402-408, 2001.
36. Watanabe $\mathrm{M}$ and Hatakeyama S: TRIM proteins and diseases. J Biochem 161: 135-144, 2017.

37. Zhan W and Zhang S: TRIM proteins in lung cancer: Mechanisms, biomarkers and therapeutic targets. Life Sci 268: 118985, 2021.

38. Tomida S, Koshikawa K, Yatabe Y, Harano T, Ogura N, Mitsudomi T, Some M, Yanagisawa K, Takahashi T, Osada H, et al: Gene expression-based, individualized outcome prediction for surgically treated lung cancer patients. Oncogene 23: 5360-5370, 2004.

39. Baylin SB and Jones PA: A decade of exploring the cancer epigenome - biological and translational implications. Nat Rev Cancer 11: 726-734, 2011.

40. Esteller M: Epigenetics in cancer. N Engl J Med 358: 1148-1159, 2008.

41. Mari-Alexandre J, Diaz-Lagares A, Villalba M, Juan O, Crujeiras AB, Calvo A and Sandoval J: Translating cancer epigenomics into the clinic: Focus on lung cancer. Transl Res 189: 76-92, 2017.

42. Clark SJ and Melki J: DNA methylation and gene silencing in cancer: Which is the guilty party? Oncogene $21: 5380-5387$, 2002.

43. You JS and Jones PA: Cancer genetics and epigenetics: Two sides of the same coin? Cancer Cell 22: 9-20, 2012.

44. Diaz-Lagares A, Mendez-Gonzalez J, Hervas D, Saigi M, Pajares MJ, Garcia D, Crujerias AB, Pio R, Montuenga LM, Zulueta J, et al: A novel epigenetic signature for early diagnosis in lung cancer. Clin Cancer Res 22: 3361-3371, 2016.

45. Liu TY, Chen J, Shang CL, Shen HW, Huang JM, Liang YC, Wang W, Zhao YH, Liu D, Shu M, et al: Tripartite motif containing 62 is a novel prognostic marker and suppresses tumor metastasis via c-Jun/Slug signaling-mediated epithelial-mesenchymal transition in cervical cancer. J Exp Clin Cancer Res 35: 170, 2016.

46. Chen N, Balasenthil S, Reuther J and Killary AM: DEAR1, a novel tumor suppressor that regulates cell polarity and epithelial plasticity. Cancer Res 74: 5683-5689, 2014

47. Tamaddoni A, Mohammadi E, Sedaghat F, Qujeq D and As'Habi A: The anticancer effects of curcumin via targeting the mammalian target of rapamycin complex 1 (mTORC1) signaling pathway. Pharmacol Res 156: 104798, 2020

48. Lane HA and Breuleux M: Optimal targeting of the mTORC1 kinase in human cancer. Curr Opin Cell Biol21: 219-229, 2009.

49. Tansey WP: Mammalian MYC proteins and cancer. New J Sci 2014: 1-27, 2014. https://doi.org/10.1155/2014/757534.

(7) This work is licensed under a Creative Commons Attribution 4.0 International (CC BY 4.0) License. 